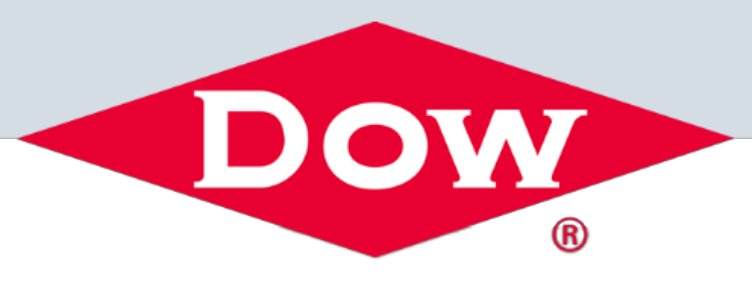

\title{
PROCESS SAFETY INCIDENT PREVENTION PROJECT: AN INITIATIVE TO REDUCE INCIDENTS ACROSS DOW LABORATORIES
}

\section{SUPPORTING INFORMATION}

Tricia L. Wilson ${ }^{1}$, Jeff J. Foisel' ${ }^{1}$, Jessica E. Nichols ${ }^{1}$, Katie A. Mulligan ${ }^{2}$

${ }^{1}$ The Dow Chemical Company, Midland, MI, 48674, USA; ${ }^{2}$ The Dow Chemical Company, Lake Jackson, TX, 77566, USA 


\section{PEROXIDE-FORMING CHEMICALS \\ Reduce risk by following storage and hanalling practices that are compatible with the properties of

\section{PEROXIDES CAN DECOMPOSE VIOLENTLY \\ Undesired peroxide (-O-O- bond) formation is possible in common lab chemicals. \\ Only hazard recognition and control can prevent a negative outcome!}

\section{Anticipate} hazard:

Explosion, exposure, injury

Limit quantity, stabilized is best!

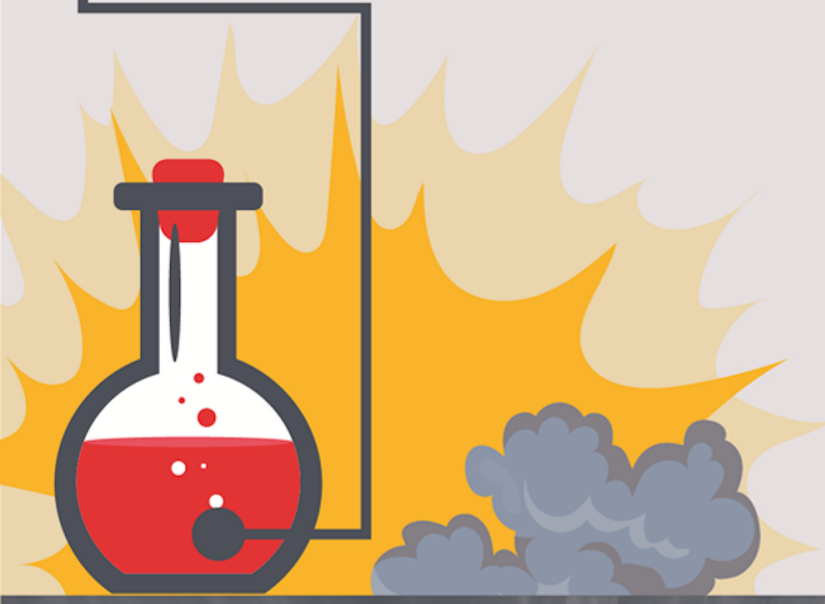

Recognize hazard:

Search literature:

SDS, "lists", etc.

Chemical family:

Determine molecular structure

Internal experts

\section{Evaluate} hazard:

Identify "class" of O-O former: $\mathrm{A}, \mathrm{B}$ or $\mathrm{C}$ ?

Use MOC/procedure to address usage

Test for -O-O- concentration

\section{Control hazard:}

- Limit shelf life

- Label expiration date

- Control inventory

Mitigate:

PPE, hood sash, blast shield
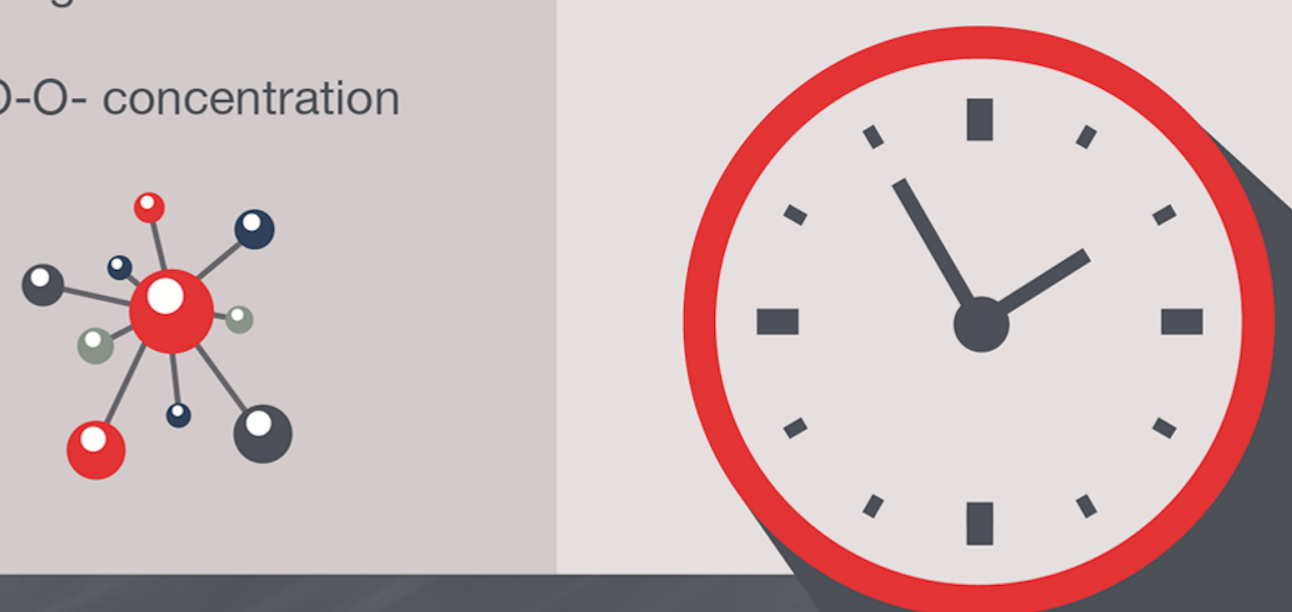